\title{
Evaluation of Leukocyte Chemotaxis In Vitro
}

\section{in Thermally Injured Patients}

\author{
Glenn D. Warden, Arthur D. Mason, Jr., and Basil A. Pruitr, Jr. \\ From the United States Army Institute of Surgical Research, Brooke Army \\ Medical Center, Fort Sam Houston, Texas 78234
}

\begin{abstract}
A в S T R A C T Leukocyte chemotaxis in vitro was studied by a modification of the Boyden technic in 46 thermally injured patients. All patients demonstrated a decrease in leukocyte migration through a Nuclepore filter toward a standard casein-serum chemotactic agent. Leukocyte chemotaxis was inversely correlated with burn size during the first $72 \mathrm{~h}$ after injury. After $72 \mathrm{~h}$, leukocyte chemotaxis directly correlated with clinical status and was highly predictive for ultimate mortality. Since mortality was largely due to infection, these findings suggest that suppression of leukocyte chemotaxis may explain the susceptibility to opportunistic infection in thermally injured patients.
\end{abstract}

\section{INTRODUCTION ${ }^{2}$}

Microbial infection continues to be the leading cause of death in thermally injured patients. Numerous conditions contribute to increased susceptibility to infection in such patients, including the presence of an open contaminated wound, increased metabolic requirements, decreased nutritional intake, loss of plasma protein into the burned area, and suppression of the patient's defense mechanisms. Investigations of leukocyte function in thermally injured patients have been reported to show normal phagocytosis and decreased intracellular bacterial killing capacity (1). The chemotactic phase of leukocyte function in such patients has not been evaluated.

Chemotaxis is presumed to be an important function of polymorphonuclear leukocytes in protection against invasive agents, for even leukocytes fully capable of ingesting and killing microorganisms are incapacitated if unable to sense and be directed toward the invading

Received for publication 19 March 1974 and in revised form 30 May 1974.

${ }^{1}$ The opinions or assertions contained herein are the private views of the authors and are not to be construed as official or as reflecting the views of the Department of the Army or the Department of Defense. pathogen. We have used a modification of the technic devised by Boyden in 1962 (2), based on the ability of leukocytes to migrate through a Nuclepore filter toward a chemotactic agent, to evaluate leukocytic chemotaxis in thermally injured patients.

\section{METHODS}

Preparation of leukocytes. On each day of testing 10 $\mathrm{cm}^{3}$ of heparinized blood (200 $\mathrm{U}$ heparin $/ 10 \mathrm{~cm}^{3}$ blood) was collected in a glass syringe. The aliquot was placed in an equal volume of $6 \%$ clinical dextran in physiologic saline solution, containing glucose $(400 \mathrm{mg} / 500 \mathrm{ml})$ and heparin $(20 \mathrm{mg} / 100 \mathrm{ml})$. Erythrocyte mononuclear sedimentation was accomplished in a $50-\mathrm{mm}$ conical tube at $37^{\circ} \mathrm{C}$ for $45 \mathrm{~min}$. The leukocyte-rich supernate was removed with a Pasteur pipette and used within $1 \mathrm{~h}$ of preparation. Average yields of $10^{8}$ cells were obtained from $10 \mathrm{ml}$ of blood. $99 \%$ viability was confirmed by the trypan blue exclusion method after sedimentation.

Chemotactic agent. Previous studies have demonstrated a mixture containing two parts of casein solution and one part of human serum to furnish reliable chemotactic attraction (3). Casein was prepared in a concentration of $5 \mathrm{mg} /$ $\mathrm{ml}$ in Hanks' solution. Human serum type AB from healthy donors was used throughout the study.

Chemotactic chamber. Perspex chambers similar to Boyden's design were used. A 2-ml aliquot of the leukocyte-rich supernate was diluted with $8 \mathrm{ml}$ Hanks' solution and $2 \mathrm{ml}$ of this mixture, containing approximately $4 \times 10^{\circ}$ cells, was placed in the upper chamber. $5 \mathrm{ml}$ of chemotactic agent (casein-serum mixture) was placed in the lower chamber. A Nuclepore filter (Nuclepore Corporation, Pleasanton, Calif.), 5- $\mu \mathrm{m}$ pore size, 25-mm diameter, was interposed between the upper and lower chambers. The chamber was incubated at $37^{\circ} \mathrm{C}$ for $120 \mathrm{~min}$. The Nuclepore filter was removed, stained with Wright-Giemsa stain for $4 \mathrm{~min}$, Wright's buffer $6 \mathrm{~min}$, cleared with xylene, and mounted with xylene-Permount ( $3: 1$ ratio) on a glass slide. The Nuclepore filter was examined microscopically under high power and the cells which had migrated through the $\mathrm{Nu}$ clepore filter (bottom side) were counted, as were the cells remaining on the starting side (top side) in each microscope field. 400 total cells were counted. Chemotaxis was evaluated in the following manner, negating the necessity to count the cells before placement in the upper 


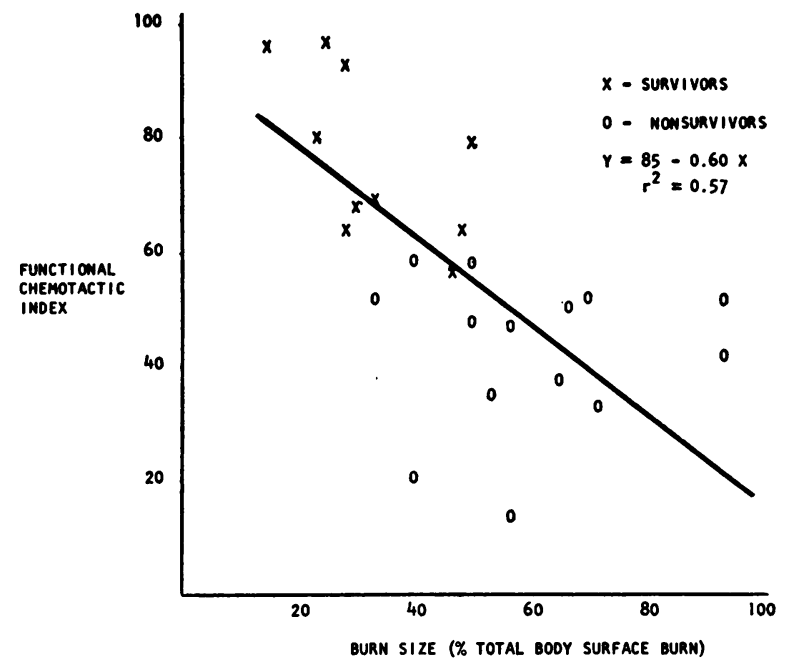

FIgURe 1 Functional chemotactic index vs. burn size during first $72 \mathrm{~h}$ post-burn.

chamber (3) :

chemotactic index $=\frac{\text { number of cells (attracting side) }}{\text { number of cells (starting side) }} \times 100$.

Leukocytes from thermally injured patients were compared with cells from normal healthy volunteers and the functional chemotactic index stated as percent of the chemotactic index of the control leukocytes :

functional chemotactic index

$$
=\frac{\text { chemotactic index burn patient }}{\text { chemotactic index normal volunteer }} \times 100 \text {. }
$$

Duplicate chambers were used for each patient sample along with a simultaneous control sample also performed in duplicate.

Experimental group. Blood was obtained from 46 thermally injured patients with an average burn size of $50.9 \%$ of total body surface and a range of $14.5-92.0 \%$. The mean age of the patients was $33.2 \mathrm{yr}$ with a range of 3-76 yr. The overall mortality among these patients was $65.2 \%$. The average burn size in those patients who expired was $59.0 \%$ (range 31.5-92.0), while the surviving patients had an average burn size of $35.9 \%$ (range 14.5-70.5). Autopsy examination was performed on 25 of the 30 nonsurviving patients. The mean day of death with 14.9 days (range 3-38 days).

Among the autopsied cases, infection as the major cause of death occurred in 23 of the 25 cases (92.0\%). Septic complications included pneumonia, burn wound sepsis, and septicemia. The mean day of clinical diagnosis of the septic complications was 9.8 days (range 3-19 days). The causative organisms included Enterobacteriaceae (4), Staphylococcus aureus (4), Providencia stuartii (7), Pseudomonas aeruginosa (4), multiple organisms (3), and Candida (1). Two patients came to autopsy without infection; one died of pulmonary embolism, the other of cerebral edema. None of the 16 surviving patients had clinical systemic septic episodes. Three had superficial infections, including thrombophlebitis of right lower extremity, staphylococcal cellulitis of donor site post-grafting, and chondritis of right ear.

Chemotaxis was measured in these patients at admission and then weekly until the patient was discharged or expired. Their burn wounds were treated topically with either $10 \%$ mafenide acetate (Sulfamylon), $0.5 \%$ silver nitrate solution or $1 \%$ silver sulfadiazine cream, using standard procedures of the Institute of Surgical Research.

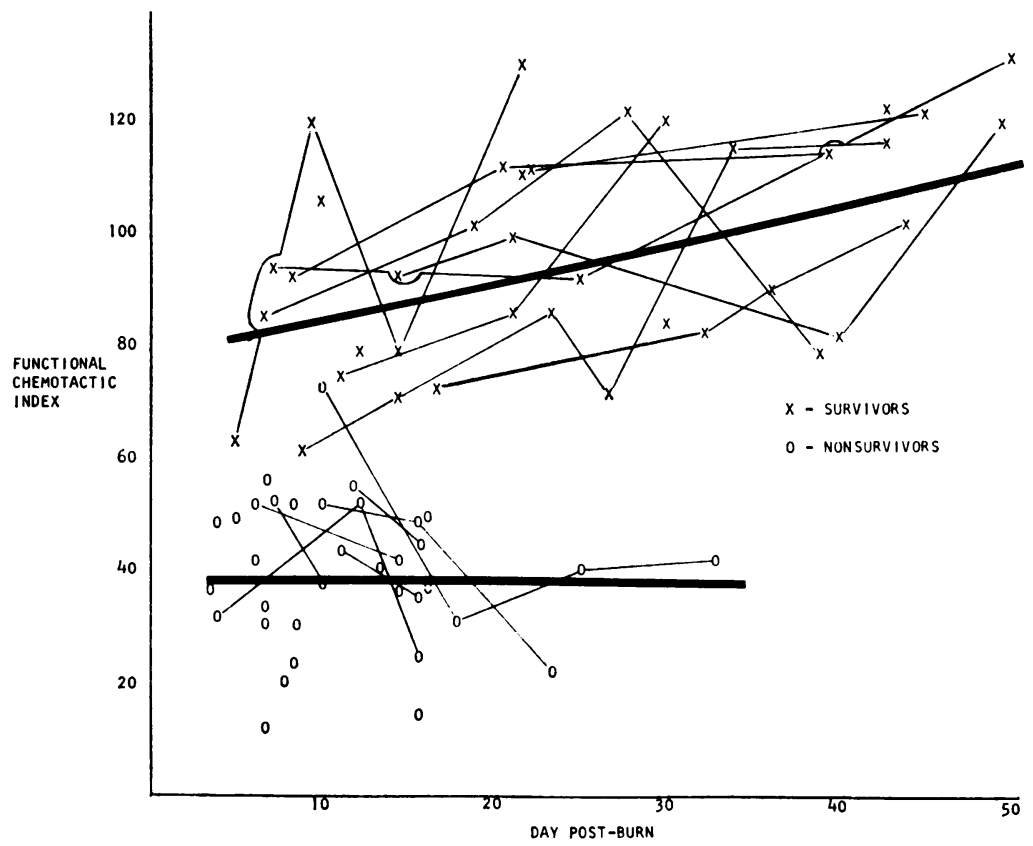

FIgURE 2 Functional chemotactic index vs. day post-burn 72 h-post-burn. 


\section{RESULTS}

As simultaneous daily control values, the chemotactic index was measured in a total of 44 normal healthy volunteers (ages 23-54 yr). A mean value of 764.4 with 95\% confidence limits of 750-780 was observed.

24 patients were studied during the first $72 \mathrm{~h}$ after injury. Burn size and functional chemotactic index were inversely related, with a regression of $Y=85.0-0.60 X$ ( $Y=$ functional chemotactic index, $X=$ burn size), and $r^{2}=0.57$ (Fig. 1).

After $72 \mathrm{~h}$, the patients separated into two groups, survivors and nonsurvivors (Fig. 2) with surviving patients demonstrating improvement in leukocyte chemotactic function during their hospital course. The nonsurviving patients demonstrated either no significant increase or a decrease in leukocyte chemotaxis from admission until death. The average functional chemotactic index in the surviving group was 97.7, $\mathrm{SE} \pm 3.2$, whereas the average index in the nonsurviving group was 39.9, $\mathrm{SE} \pm 2.3$ (Table I). Individual functional chemotactic indices after $72 \mathrm{~h}$ correlated closely with the overall clinical status of the patient. No patient with a functional chemotactic index below 60 survived beyond $72 \mathrm{~h}$ after injury; only one patient with an index greater than 60 expired. Statistical comparison revealed a significant difference between the mean indices of these groups $(P \ll 0.01)$. Diminished chemotactic function was observed before clinical infection in all patients who ultimately succumbed to infection. The onset of clinical infection was not associated with any change in the functional index. Functional chemotactic index did not vary with either the agent used for topical chemotherapy or with other identifiable differences in treatment. Age and sex were also without effect.

\section{DISCUSSION}

Chemotaxis is an important biologic phenomenon, determining the direction of motion of bacterial, plant, and animal cells in reproduction, nutrition, cellular organization, and inflammation. Various methods have been used to study chemotaxis but the technic of Boyden has been the most useful because of its simplicity and reproducibility. A number of modifications of this technic have been devised (3-7). Leukocytes show directional migration toward many polysaccharides, polypeptides, and proteins. The action of certain of these substances on the cells is direct and the term cytotaxin has been used to define these direct acting agents; some substances, which have no direct effect, exert an indirect (chemotaxogenic) action on leukocytes through activation of mediators present in serum. These chemotaxogens include antigen-antibody complexes, xymocytotaxi-
TABLE I

Functional Chemotactic Index 72 h Post-Burn

\begin{tabular}{lcc}
\hline & Survivors & $\begin{array}{c}\text { Non- } \\
\text { survivors }\end{array}$ \\
\hline Number of patients & 12 & 23 \\
Number of determinations & 36 & 34 \\
Functional chemotactic index & 97.7 & 39.9 \\
SE & 3.2 & 2.3 \\
Range & $61.2-130$ & $14.6-75$ \\
Significance & $P=\ll 0.01$ & $P=\ll 0.01$ \\
Burn size & 44.6 & 57.9 \\
Range & $25.5-70.5$ & $31.5-92.0$ \\
\hline
\end{tabular}

gens, bacterial liposaccharides, plasminogen, and streptokinase. Chemotactic factors or cytotaxins are numerous and varied and there is a constantly growing list of complement-dependent and non complement-dependent factors chemotactic for polymorphonuclear leukocytes.

Other immunologic investigations in thermally injured patients have reported correlations between infection and specific immunologic defects $(1,7,8)$, but no correlation between the extent of trauma and the severity of the defect. This study demonstrates leukocyte chemotaxis to be inversely related to the extent of burn trauma and correlated with subsequent mortality. In nonsurviving patients leukocyte chemotaxis was decreased on admission and remained decreased throughout the entire hospital course. Thus the decrease in leukocyte chomotaxis ocurred before the onset of clinical infection.

The pathophysiology of the decreased leukocyte chemotaxis remains to be elucidated and a causal relationship between the decreased leukocyte chemotaxis and subsequent infection can only be theorized. However, the predictive value of leukocyte chemotaxis for ultimate mortality was extremely high and this mortality was largely due to infection. It thus seems possible that the relationship between burn injury and suppression of leukocyte chemotaxis may explain the susceptibility to opportunistic infection which is the hallmark of major thermal injury.

\section{REFERENCES}

1. Alexander, J. W., and D. Wixon. 1970. Neutrophil dysfunction and sepsis in burn injury. Surg. Gynecol. Obst. 130 : 431-438.

2. Boyden, S. 1962 . The chemotactic effect of mixtures of antibody and antigen on polymorphonuclear leukocytes. J. Exp. Med. 115 : 453-466.

3. Baum, J., A. G. Mowat, and J. A. Kirk. 1971. A simplified method for the measurement of chemotaxis of polymorphonuclear leukocytes from human blood. J. Lab. Clin. Med. 77 : 501-509. 
4. Ward, P. A., I. H. Lepow, and L. J. Newman. 1968 Bacterial factors chemotactic for polymorphonuclear leukocytes. Am. J. Pathol. 52: 725-736.

5. Ward, P. A. 1968. Chemotaxis of mononuclear cells. $J$. Exp. Med. 128: 1201-1221.

6. Zigmond, S. H., and J. G. Hirsch. 1973. Leukocyte locomotion and chemotaxis: new methods for evaluation and demonstration of a cell-derived chemotactic factor. $J$. Exp. Med. 137 : 387-410.
7. Alexander, J. W., and J. A. Moncrief. 1966. Alterations of the immune response following severe thermal injury. Arch. Surg. $93:$ 75-83.

8. Curreri, P. W., E. L. Heck, L. Browne, and C. R. Baxter. 1973. Stimulated nitroblue tetrazolium test to assess neutrophil antibacterial function: prediction of wound sepsis in burned patients. Surgery (St. Lonis). $74: 6-13$. 